\title{
Diagnostic characterization of ablation plasma ion implantation
}

\author{
B. Qi, R. M. Gilgenbach, ${ }^{a)}$ M. C. Jones, M. D. Johnston, Y. Y. Lau, \\ L. M. Wang, and J. Lian \\ Nuclear Engineering and Radiological Sciences Department, Intense Energy Beam Interaction Laboratory, \\ The University of Michigan, Ann Arbor, Michigan 48109-2104
}

G. L. Doll and A. Lazarides

Advanced Materials $R \&$ D, Timken Research, The Timken Corporation, Canton, Ohio 44706-0939

(Received 6 November 2002; accepted 17 February 2003)

\begin{abstract}
Experiments are reported in which two configurations for ablation-plasma-ion-implantation (APII) are characterized by diagnostics and compared. The first configuration oriented the target parallel to the deposition substrate. This orientation yielded ion-beam-assisted deposition of thin films. A delay $(>5 \mu \mathrm{s})$ between laser and high voltage was necessary for this geometry to avoid arcing between negatively biased substrate and target. The second experimental configuration oriented the target perpendicular to the deposition substrate, reducing arcing, even for zero/negative delay between the laser and the high voltage pulse. This orientation also reduced neutral atom, ballistic deposition on the substrate resulting in a pure ion implantation mode. Ion density measurements were made by resonant laser diagnostics and Langmuir probes, yielding total ion populations in the range of $10^{14}$. Implanted ion doses were estimated by electrical diagnostics, and materials analysis, including x-ray energy dispersive spectroscopy and $\mathrm{x}$-ray photoelectron spectroscopy, yielding implanted doses in the range $10^{12}$ ions $/ \mathrm{cm}^{2}$ per pulse. This yields an APII efficiency of order $10 \%$ for implantation of laser ablated ions. Scaling of ion dose with voltage agrees well with a theory assuming the ChildLangmuir law and that the ion current at the sheath edge is due to the uncovering of the ions by the movement of the sheath. Thin film analysis showed excellent adhesion with smoother films for an accelerating voltage of $-3.2 \mathrm{kV}$; higher voltages $(-7.7 \mathrm{kV})$ roughened the film. (C) 2003 American Institute of Physics. [DOI: 10.1063/1.1565822]
\end{abstract}

\section{INTRODUCTION}

Plasma-immersed-ion implantation (PIII) has undergone enormous growth since the pioneering experiments of Conrad. ${ }^{1-4}$ PIII treatment of materials has seen applications to hardening of tools, ion implantation for semiconductor electronics, and, most recently, improved biocompatibility of biomedical implants. ${ }^{5-12}$ Ion source plasmas have been generated by thermionic cathodes, radio frequency, microwaves, magnetron sputtering, and vacuum arc discharges. ${ }^{1-9}$ Over the past several years, experiments and theory have been performed at the University of Michigan concerning the utilization of $\mathrm{KrF}$ laser ablation plasmas as the ion source for implantation. ${ }^{10-12}$ This process, known as ablation-plasmaion-implantation (APII), has a number of advantages. APII can generate ion source plasmas directly from any solid material, even refractories and compounds. APII requires no toxic precursor gases, (e.g., silane for $\mathrm{Si}$ or diborane for B). Furthermore, we demonstrate here that relatively high ion doses can be generated by APII for implantation of moderate area substrates.

This article presents a comprehensive diagnostic characterization of the process of ablation-plasma-ion implantation. Optical plasma diagnostics ${ }^{13}$ (resonant $^{14} /$ nonresonant laser interferometry), and electrical plasma diagnostics, (current

\footnotetext{
${ }^{a)}$ Author to whom correspondence should be addressed; electronic mail: rongilg@umich.edu
}

and Langmuir probes) have been applied, as well as an array of materials diagnostics to analyze the deposited and implanted films. Two alternative APII experimental configurations have been developed and compared, each having distinct advantages for either ion-beam-assisted deposition (IBAD) or pure ion implantation. Finally, ion dose measurements and estimates are summarized and compared for the two configurations. Scaling laws for the implanted ion current, that corroborate experiments, are constructed for the parallel target-substrate configuration.

\section{EXPERIMENTAL CONFIGURATION}

Two APII experimental configurations are depicted schematically in Fig. 1. The first APII experiment, explored most intensively, utilizes the standard orientation for pulsed laser deposition, ${ }^{10-12}$ in which the substrate and target surfaces are oriented parallel to one another [Fig. 1(a)]. The physical basis of this orientation is that the ablation plume constituents (electrons, ions, neutral atoms and particulate) are ejected primarily perpendicularly to the target for direct, ballistic impact with the substrate. Therefore, neutral atoms are deposited and ions are implanted, analogous to IBAD. Targets consist either of iron (briefly reported earlier ${ }^{11}$ ) or titanium, the subject of this article. Substrates are either Si wafers or Al alloy disks (6061). The target in these experiments is a rotating pyramid, which wobbles the ablation plume for more uniform deposition over a larger substrate area (up to 


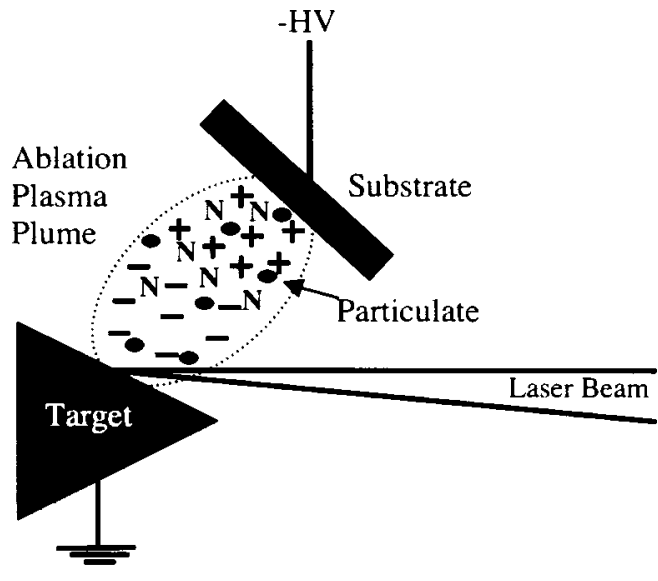

(a)

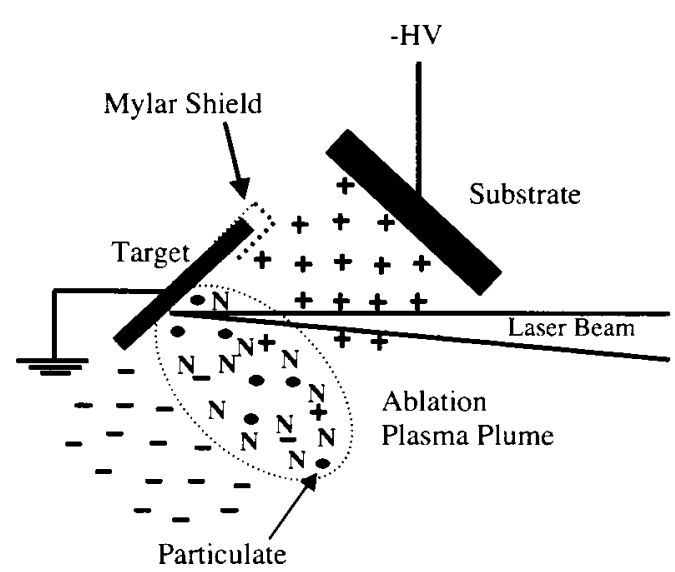

(b)

FIG. 1. Experimental configurations for two geometries of APII: (a) target parallel to substrate and (b) target perpendicular to substrate.

$8 \mathrm{~cm}^{2}$ in these experiments). The substrate is pulse biased negatively up to a peak of $-10 \mathrm{kV}$. One problem with this configuration was arcing at short $(<5 \mu \mathrm{s})$ delay times between the KrF laser pulse and the high voltage pulse. Such arcing was avoided because it punched holes in deposited films.

In order to address the problem of arcing, a second, more recent, experimental configuration ${ }^{10}$ orients the target perpendicular to the substrate [Fig. 1(b)]. Electrons are expelled from the gap between target and substrate, reducing the source of arcing. Extremely small ballistic deposition of plume neutral atoms is expected on the substrate. However, the negatively biased substrate accelerates the ablated ions to the substrate, so one expects pure ion implantation in this case. Experimental results will bear out these statements. Ballistic deposition of laser-ablated particulate ${ }^{15}$ is also reduced in the perpendicular orientation.

The ablation laser is a $\mathrm{KrF}$ laser (Lambda-Physik Compex 205) which generates up to $600 \mathrm{~mJ}$ at a wavelength of $248 \mathrm{~nm}$ in a $20 \mathrm{~ns}$ pulse, detected by a P-intrinsic-N (PIN) diode. This laser is typically operated at a repetition rate of 10 pps for APII deposition. The laser beam is focused to a fluence on the target between $5-20 \mathrm{~J} / \mathrm{cm}^{2}$. The APII chamber is a turbomolecular-pumped, six-way cross with large, fused-silica side diagnostic ports for optical diagnostics.

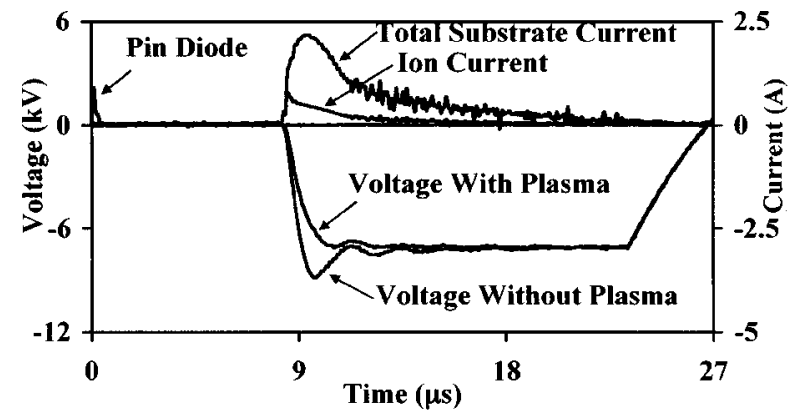

(a)

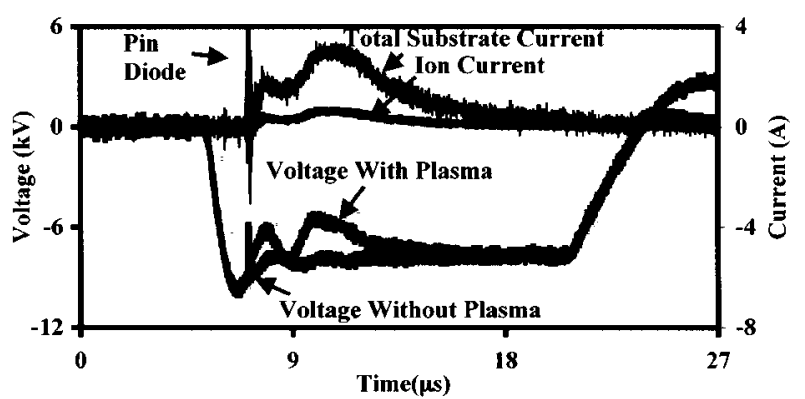

(b)

FIG. 2. Experimental wave forms for APII: (a) target parallel to substrate and (b) target perpendicular to substrate.

Base vacuum is on the $10^{-6}$ Torr scale, (which accounts for the significant oxygen content seen in film analysis of a later section).

A number of plasma diagnostics are employed to characterize the APII process. ${ }^{13,14}$ Nonresonant dye laser interferometry measures electron densities. Dye-laser resonance absorption photography establishes the streaming velocities of the neutral atoms and ions. ${ }^{13}$ Resonant interferometry is utilized to measure the absolute density of ions in the laser ablation plume. ${ }^{14}$ Optical emission spectroscopy $(0.3 \mathrm{~m}$ spectrograph with gated, intensified charge coupled device) characterizes the ablated plasma species and electron temperature from atomic Boltzmann plots. At later times in the plume expansion, the density is significantly reduced, so Langmuir probes (single and double) are employed to measure ion density and electron temperature and density.

A variety of material analysis diagnostics are employed to analyze APII films, including: scanning electron microscopy, transmission electron microscopy (TEM), x-ray photoelectron spectroscopy (XPS), x-ray energy dispersive spectroscopy (XEDS), atomic force microscopy (AFM), and scratch tests.

\section{EXPERIMENTAL RESULTS}

Electrical signals from APII are represented in Fig. 2. The upper signals (a) obtained for the target orientation parallel to the substrate, show that, in order to avoid arcing, a delay time of about $8 \mu$ s was utilized between the laser pulse and the beginning of the high voltage pulse. The peak overshoot of the applied voltage (without laser ablation plasma) reached about $-9 \mathrm{kV}$. With ablation plasma present, the peak voltage was reduced to about $-7.1 \mathrm{kV}$, with a flattop of 


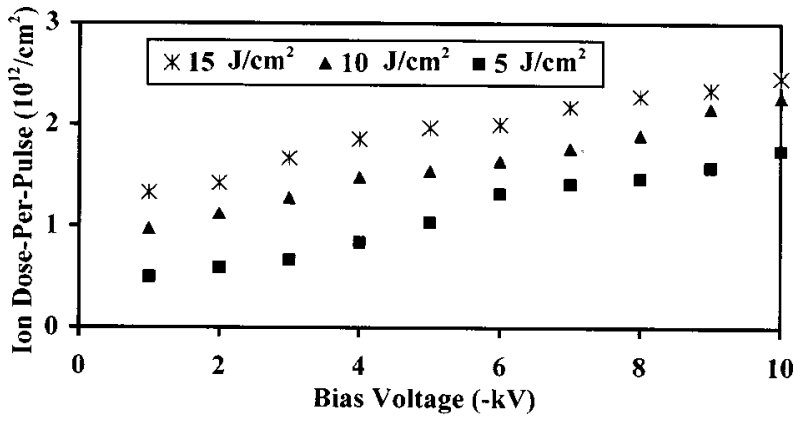

(a)

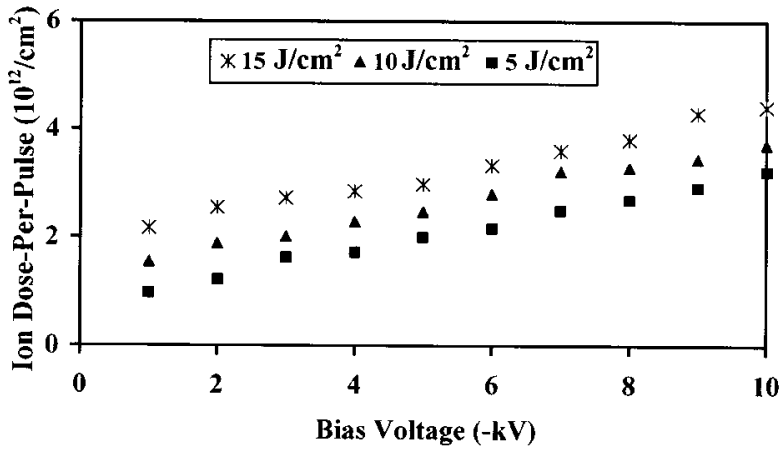

(b)

FIG. 3. Ti ion dose-per-pulse obtained from integrated ion current: (a) target parallel to substrate and b) target perpendicular to substrate.

$-7.1 \mathrm{kV}$. Full voltage is maintained for a duration of about $13 \mu \mathrm{s}$. The total substrate current signal, exceeding the $2 \mathrm{~A}$ peak, includes: (primarily) secondary electron current, (small) displacement current, and ion current. When secondary electron and displacement currents are subtracted, the ion current signal is shown, with a peak of about $0.7 \mathrm{~A}$, decaying during the pulse. Note that the initial spike of ion current is accelerated at low energy during the voltage risetime; by the time the voltage has reached its full value the current has fallen by a factor of 2 . It will be shown later that the large delay time results in a significantly reduced ion density due to recombination. The comparison of the current data with theory is postponed until Sec. IV.

APII electrical signals for the perpendicular orientation of the target and substrate [Fig. 2(b)] show that the laser pulse can be applied after the voltage has reached its peak without arcing. This high plasma density leads to significantly larger total current signals, over 3 A peak; of this current, nearly 0.7 A represents ion current. Pulsing the laser at the peak of the voltage has the advantage that the initially high ion current is accelerated to nearly full energy. These high total currents apparently load down the power supply, producing some voltage droop (to $-6 \mathrm{kV}$ ).

Integration of these ion current data signals for a variety of laser fluences and bias voltages yields the APII ion dose data shown in Fig. 3. These data show several important APII scalings. Note that the total ion dose, on the order of $10^{12} \mathrm{ion} / \mathrm{cm}^{2}$ per pulse, is on the high-end of doses observed in conventional PIII. The scaling of ion dose with laser fluence $\left(\mathrm{J} / \mathrm{cm}^{2}\right)$ yields about $0.5 \times 10^{12} / \mathrm{cm}^{2}$ increase in ions for every $5 \mathrm{~J} / \mathrm{cm}^{2}$ of additional laser fluence; this gives a scaling



FIG. 4. Ion densities profiles as a function of time measured at 1.1,2.2, and $3.3 \mathrm{~cm}$ in front of target by the single Langmuir probe. Laser fluence was $10 \mathrm{~J} / \mathrm{cm}^{2}$. Target parallel to the substrate.

factor of $0.1 \times 10^{12} \mathrm{ions} / \mathrm{J} / \mathrm{cm}^{2}$, only weakly dependent upon voltage. Finally, the perpendicular orientation of target and substrate yields a factor of two higher ion dose than the parallel orientation, apparently due to the longer ion current pulse resulting from the lowered ion-electron recombination at early times.

Numerous plasma diagnostics have been performed on APII to characterize the ion density. The data presented in Fig. 4 were obtained by Langmuir probes. These data represent ion densities obtained from ion saturation currents taken versus time at several different distances from the target. As seen in the figure, the ion densities decrease from a peak of $10^{20}$ to $10^{18} \mathrm{~m}^{-3}$ during the $8-9 \mu$ s delay time typically employed for the parallel APII orientation. This hundredfold reduction of ion density is due both to plasma expansion and electron-ion recombination. These densities will be utilized for comparison to ion doses in Sec. IV.

Resonant interferometry was utilized for measurement of the absolute density of ions by the Ti ion near-ground-state transition at $376.312 \mathrm{~nm}$. Detuning of the laser was in the range of $0.017 \mathrm{~nm}$ to avoid strong resonant absorption. Figure 5 shows the total number of titanium ions, in $\mathrm{Ti}$ nearground-state transition at $376.312 \mathrm{~nm}$. By assuming a Boltzmann distribution with a temperature of about $1 \mathrm{eV}$, one finds the total ion number is approximately 273 times higher than the number of ions measured in the Ti near-ground-state transition at $376.312 \mathrm{~nm}$. This calculation yields a maximum of $4.6 \times 10^{14}$ total $\mathrm{Ti}$ ions in the laser ablation plume.

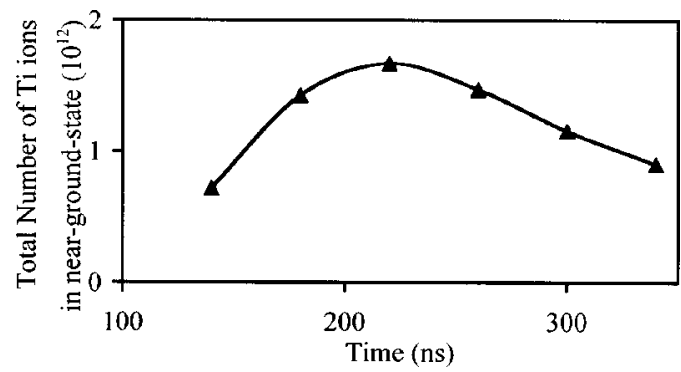

FIG. 5. Plot of the total number of Ti ions in near-ground state as a function of time for $5 \mathrm{~J} / \mathrm{cm}^{2}$ laser fluence. Total number of ions is 273 times higher, assuming a Boltzman distribution at $1 \mathrm{eV}$ electron temperature. Target parallel to the substrate. 


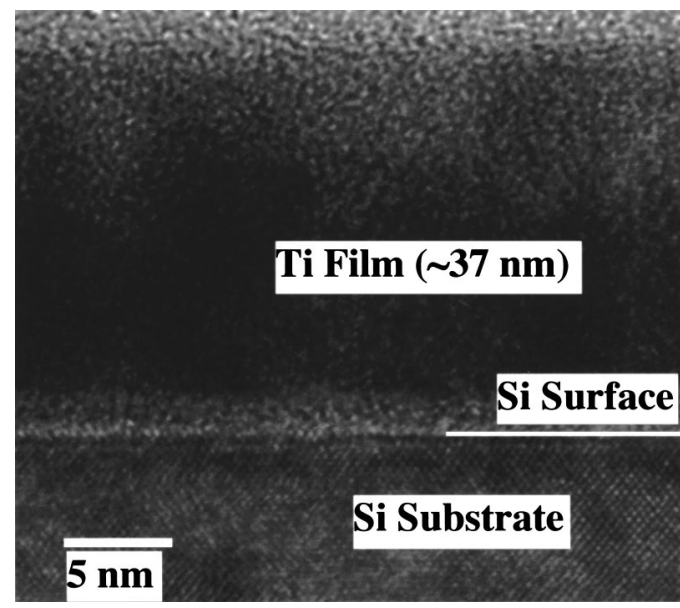

FIG. 6. Cross-sectional TEM photograph of the baseline film $(0 \mathrm{kV})$ of Ti deposited on the Si substrate for target parallel to substrate geometry. The laser fluence was $10 \mathrm{~J} / \mathrm{cm}^{2}$ and the distance between the ablation spot and substrate was $3.9 \mathrm{~cm}$. The total number of laser pulses was 3600 .

Electron densities were also measured by nonresonant interferometry (of Fe ablation). These data, not shown here, yielded electron densities in the range of $10^{24} \mathrm{~m}^{-3}$ at early times (0-20 ns after the laser pulse) decaying to the $10^{23} \mathrm{~m}^{-3}$ level after about $50-90 \mathrm{~ns}$. Electron densities were a factor of 3 higher for a laser fluence of $39 \mathrm{~J} / \mathrm{cm}^{2}$ compared to $10 \mathrm{~J} / \mathrm{cm}^{2}$ fluence.

Figure 6 presents cross-sectional TEM data of a baseline film $(0 \mathrm{kV})$ of Ti deposited by laser ablation on a Si substrate for the parallel orientation of target and substrate (spacing of $3.9 \mathrm{~cm}$ ). The laser fluence was $10 \mathrm{~J} / \mathrm{cm}^{2}$ and the number of laser pulses utilized for the deposition was 3600. Thickness of the Ti films was $37 \mathrm{~nm}$, yielding a deposition rate of 0.01 $\mathrm{nm} / \mathrm{shot}$. Other TEM data indicate that this Ti film possesses a nanocrystalline structure.

Cross-sectional TEM data in Fig. 7(a) depict an APII film deposited at an applied bias voltage of $-8 \mathrm{kV}$ flattop. Delay time between laser and voltage was $8 \mu \mathrm{s}$. The orientation (parallel target-substrate), spacing, laser fluence, and number of shots are the same as the baseline film of Fig. 6 . In contrast to the baseline film, the APII films shows a $15 \mathrm{~nm}$ deep damage layer, caused by ion implantation and cascades. Transport of Ions in Matter (TRIM) code calculations with ion energy of $8 \mathrm{kV}$ are depicted in Fig. 7(b). The ion penetration depth is expected to be lower than predicted by TRIM: (1) later implanted ions must penetrate the overlying Ti film, and (2) ions are accelerated during the slow risetime of the voltage (only in the parallel target-substrate orientation). The overlying, amorphous Ti film is $27 \mathrm{~nm}$ thick, some $10 \mathrm{~nm}$ thinner than the baseline film. Causes of the thinner APII film are the implantation of ions, densification of the films by ion bombardment, and ion-sputtering of Ti from the surface. The APII film deposition rate in the parallel orientation is $0.0075 \mathrm{~nm} / \mathrm{shot}$. Therefore, the APII parallel targetsubstrate orientation produces films that resemble IBAD.

For the perpendicular orientation of target and substrate the baseline $(0 \mathrm{kV})$ laser deposited film is shown in the cross-sectional TEM photograph of Fig. 8. It can be seen the ballistic expansion of the laser ablation plume, primarily per-

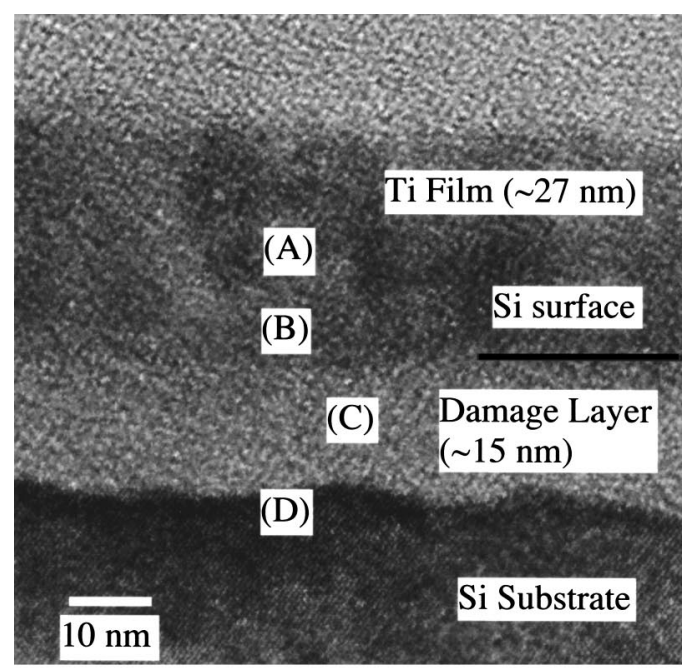

(a)

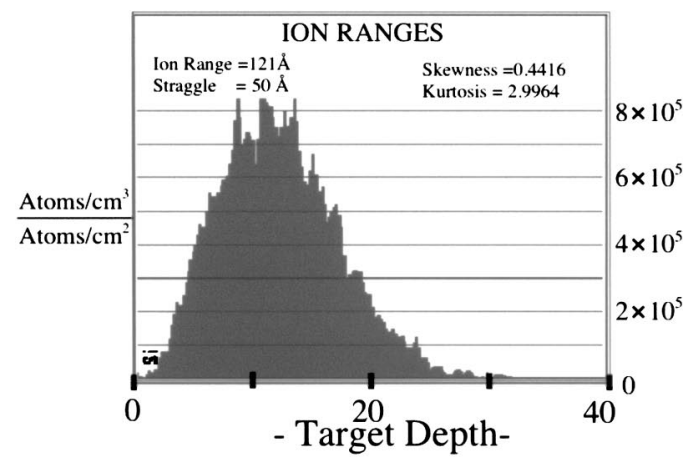

(b)

FIG. 7. (a) Cross-sectional TEM photograph of the APII film ( $-8 \mathrm{kV}$ flattop) of Ti deposited on the Si substrate for target parallel to substrate geometry. The laser fluence was $10 \mathrm{~J} / \mathrm{cm}^{2}$ and the distance between the ablation spot and substrate was $3.9 \mathrm{~cm}$. The total number of laser/HV pulses was 3600. Locations labeled with (A), (B), (C), and (D) were analyzed by XEDS (see FIG. 10). (b) Ion ranges simulated by TRIM code with an ion effective energy of $8 \mathrm{kV}$.

pendicular to the target, deposits negligible film on the substrate. Laser fluence was $10 \mathrm{~J} / \mathrm{cm}^{2}$, for 3600 pulses and the ablation spot was $3.9 \mathrm{~cm}$ from the substrate.

When the APII voltage of $-7.6 \mathrm{kV}$ flattop is applied (with zero delay time) in the perpendicular orientation, the film represented in Fig. 9 is obtained. Here, there is no overlying film, but the ion induced damage layer depth is $23 \mathrm{~nm}$, some $50 \%$ deeper than the parallel orientation. This is due to several factors, including the absence of the overlying Ti film and the fact that the laser is fired at the same time as the high voltage pulse, yielding full-energy ions. Thus, the APII perpendicular target-substrate orientation yields a pure ion implantation mode, in which only ions are accelerated and implanted in the film; neutral-atom deposition is eliminated. Another major advantage is that laser ablated particulate deposition on the substrate is also reduced in this orientation.

Figure 10 summarizes XEDS spectra, which have been measured for the data and locations of the APII (parallel orientation) film in Fig. 7(a). From these data, atomic concentrations have been calculated. As seen in Fig. 10(A), the overlying film [region (A) in Figs. 7(a) and 10(A)] is com- 


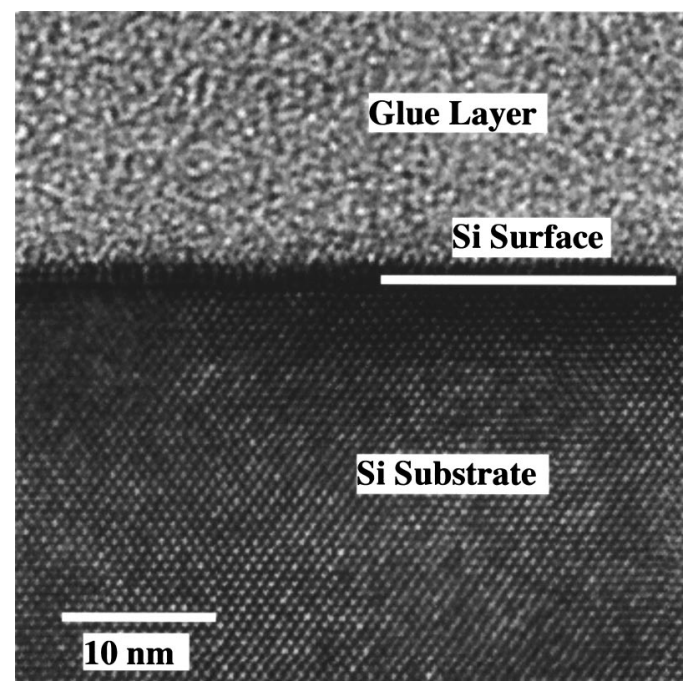

FIG. 8. Cross-sectional TEM photograph of the baseline film $(0 \mathrm{kV})$ of $\mathrm{Ti}$ deposited on the Si substrate for target perpendicular to substrate geometry. The laser fluence was $10 \mathrm{~J} / \mathrm{cm}^{2}$ and the distance between the ablation spot and substrate was $3.9 \mathrm{~cm}$. The total number of laser pulse was 3600 .

posed primarily of $\mathrm{Ti}(51 \%)$, with small $\mathrm{Si}$ concentration $(10 \%)$, and with significant $\mathrm{O}$ contamination $(31 \%)$ due to the $10^{-6}$ Torr vacuum. Closer to the original surface of the $\mathrm{Si}$ [(B) in Figs. 7(a) and 10(B)], the film is mostly Ti (55\%), but $\mathrm{Si}$ concentration has increased to $17 \%$; oxygen content is $28 \%$. Within the damage layer, [(C) in Figs. 7(a) and 10(C)], silicon predominates $(71 \%)$, but implanted Ti atoms are detected at significant concentration (17\%). Below the implantation depth [(D) in Figs. 7(a) and 10(D)], primarily Si (96\%) is detected, with $2 \%$ Ti. These data prove that ablated Ti ions are implanted into the $\mathrm{Si}$ substrate.

Finally, atomic force microscopy and tribological tests were performed at Timken Research. AFM data are presented in Fig. 11; the baseline $(0 \mathrm{kV})$, laser deposited film is shown in Fig. 11(a). The film exhibits a rough structure with

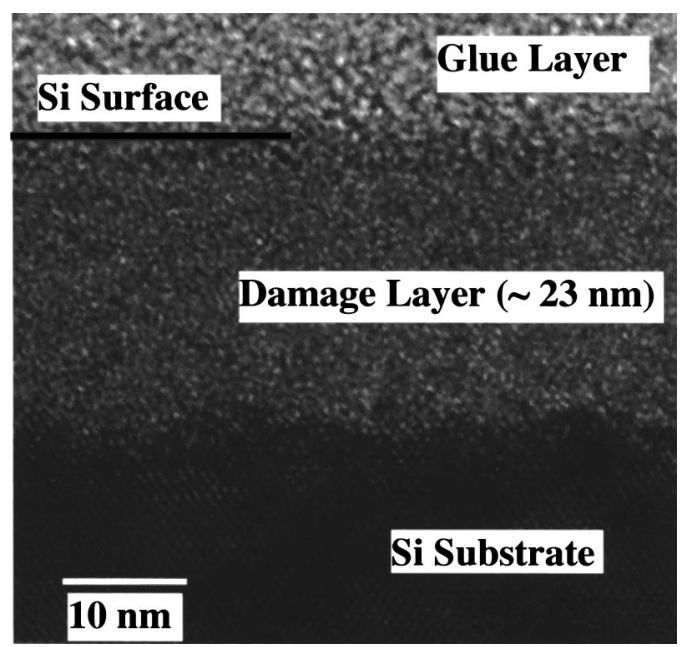

FIG. 9. Cross-sectional TEM photograph of the APII film ( $-7.6 \mathrm{kV}$ flattop) of $\mathrm{Ti}$ deposited on the $\mathrm{Si}$ substrate for target perpendicular to substrate geometry. The laser fluence was $10 \mathrm{~J} / \mathrm{cm}^{2}$ and the distance between the ablation spot and substrate was $3.9 \mathrm{~cm}$. The total number of laser/HV pulses was 3600 .

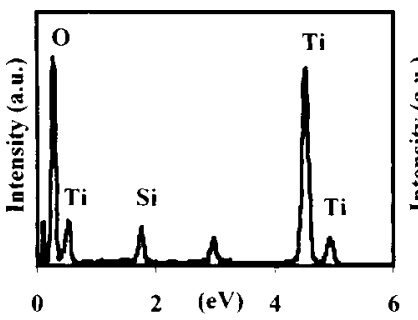

(A)
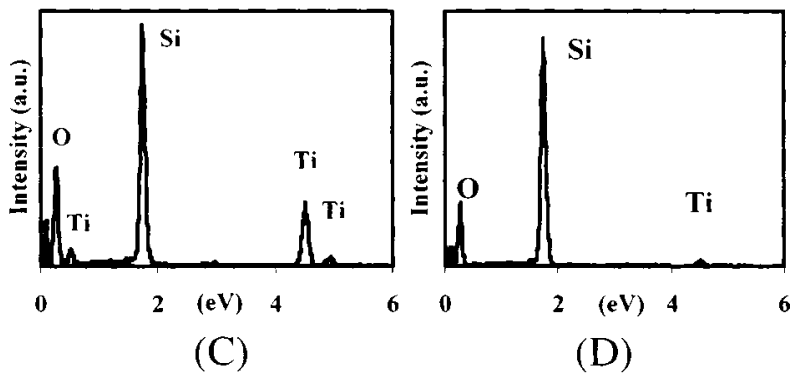

FIG. 10. XEDS spectra measured for calculation of atomic concentration at different locations on the sample. Locations measured on the $-8 \mathrm{kV}$ flattop APII sample are labeled in Fig. 7(a).

the expected columnar growth. AFM data for the APII Ti film at $-3.2 \mathrm{kV}$ flattop, shown in Fig. 11(b), indicate a smoother film than the baseline. For an accelerating voltage of $-7.7 \mathrm{kV}$ flattop, the film became rough, similar to the

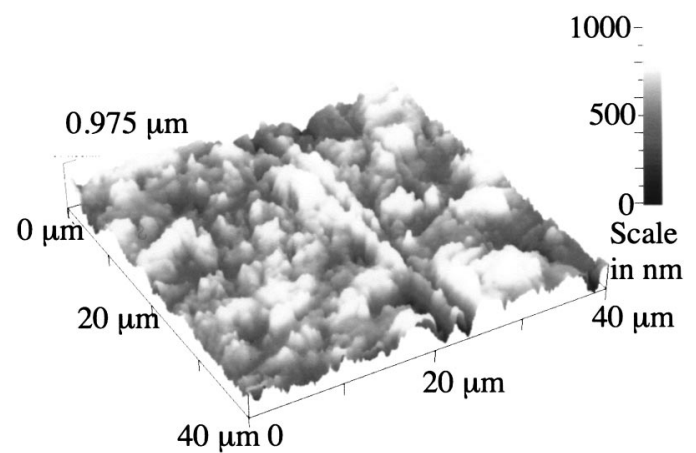

(a)

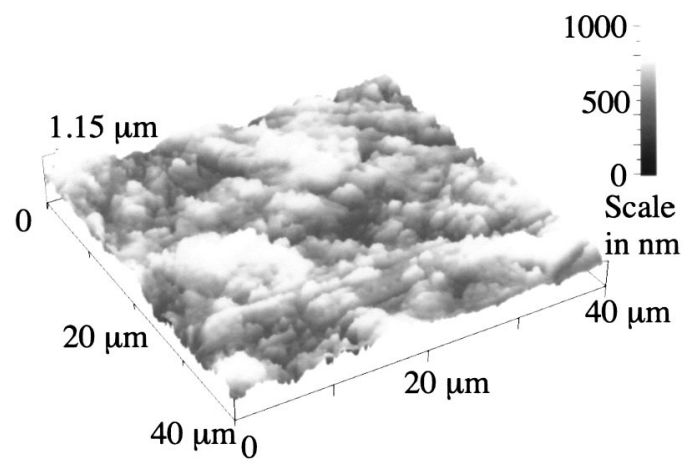

(b)

FIG. 11. (a) AFM image of Ti deposited on the Al 6061 alloy substrate. The laser fluence was $10 \mathrm{~J} / \mathrm{cm}^{2}$. Target parallel to the substrate. Baseline film $(0$ $\mathrm{kV}$ ). (b) AFM image of Ti deposited on the Al 6061 alloy substrate. The laser fluence was $10 \mathrm{~J} / \mathrm{cm}^{2}$. Target parallel to the substrate. APII film at $-3.2 \mathrm{kV}$ flattop. 
baseline film, probably due to sputtering and redeposition. Scratch tests were also performed, indicating excellent adhesion of films with no delamination. Friction coefficient measurements showed that the $-3.2 \mathrm{kV}$ APII film had slightly lower friction coefficient, than the baseline and $-7.7 \mathrm{kV}$ films. Thus, APII can be utilized to deposit smoother films with potentially lower friction.

\section{THEORY OF APII}

Previous theoretical research calculated the implanted ion current in terms of the (early time) ion matrix sheath implantation. ${ }^{12}$ In the present article, for comparison with experiments (parallel target-substrate orientation), we explore the late time Child sheath implantation model, which has also been studied in the literature. While existing models on Child sheath implantation may still have several unresolved issues, ${ }^{16-19}$ these have successfully been used to interpret experimental results on PIII. ${ }^{20}$ Here, we simplify such a theory to explain the long-time scale of the implanted ion current profile observed in our experiment. This theory, together with the newly constructed scaling laws, is given in detail in the Appendix. Chiefly, if the Child-Langmuir law is assumed, and the ion current at the sheath edge is due to the uncovering of the ions by the movement of the sheath and to the ions' motion across the sheath boundary at velocity, ${ }^{20,21}$ $\nu_{s}$, one obtains

$$
q n_{0}\left(\frac{d s}{d t}+\nu_{s}\right)=j_{i}=\frac{4}{9} \varepsilon_{0}\left(\frac{2 q}{M}\right)^{1 / 2} V_{s}^{3 / 2} / s^{2} .
$$

In Eq. (1), $s$ is the sheath thickness, $V_{s}$ is the magnitude of the bias voltage, and $\nu_{s}$ is of order the Bohm velocity. If we ignore $\nu_{s}$, which may be justified for a very long voltage pulse that has a relatively sharp risetime $\tau$, we may establish the scaling law for the implanted ion current [cf. Eq. (A5) of Appendix]

$$
\begin{aligned}
I_{i}= & (0.583 \mathrm{~A})\left(\frac{1}{M_{i} / 50 m_{p}}\right)^{1 / 6}\left(\frac{n_{0}}{10^{18} \mathrm{~m}^{-3}}\right)^{2 / 3} \\
& \times\left(\frac{V_{0}}{10 \mathrm{kV}}\right)^{1 / 2}\left(\frac{1}{\tau / 1 \mu \mathrm{s}}\right)^{2 / 3}\left(\frac{A}{10 \mathrm{~cm}^{2}}\right),
\end{aligned}
$$

where $I_{i}$ is the implanted ion current; $M_{i}$ is the mass of implanted ions; $m_{p}$ is the proton mass; $n_{0}$ is the plasma density; $V_{0}$ is the bias voltage; $\tau$ is the risetime (roughly the $R C$ time constant of the external circuit) of the bias voltage; and $A$ is the substrate area.

The total substrate current can be expressed as

$$
j_{\text {total }}=j_{i}(1+\delta) \text {, }
$$

where $\delta$ is the secondary electron emission coefficient and is a function of the ion energy.

The implanted ion peak current may be readily estimated by inserting the experimental parameters into Eq. (2). The ion current as a function of time can be obtained by solving Eq. (1) with an assumed bias voltage profile $V_{s}(t)$. Figure 12 shows excellent agreement of the theory with the measured total substrate current (a) and ion current (b); (see Appendix).

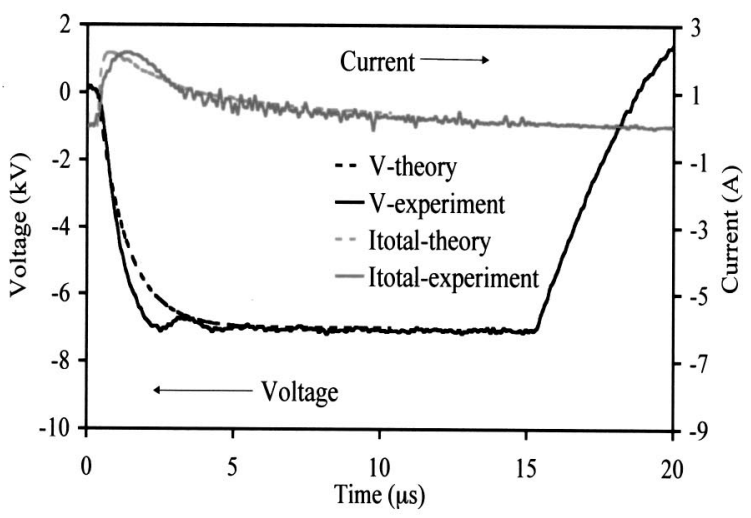

(a)

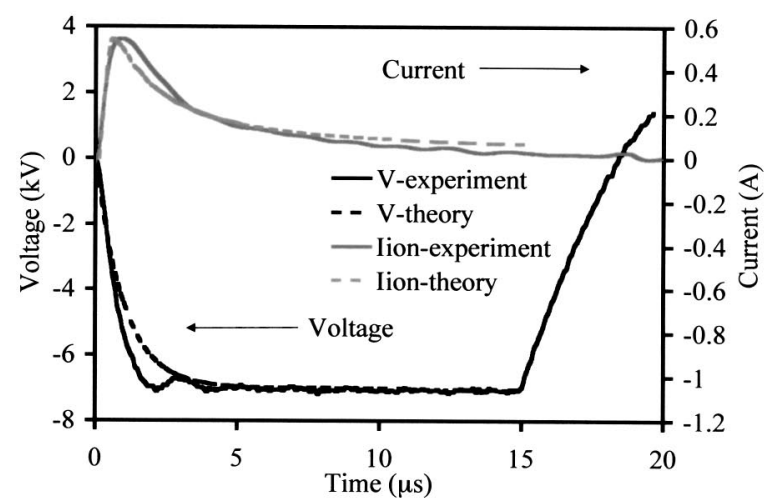

(b)

FIG. 12. Comparison between theory and experiment for the substrate parallel to target geometry: (a) total substrate current and (b) ion current.

\section{DATA SUMMARY AND CONCLUSIONS}

This section correlates the plasma diagnostic data with the deposited films data to analyze the efficiency of the APII process. Table I summarizes the plasma parameters measured for APII. Peak ion densities in the range $10^{20} \mathrm{~m}^{-3}$ were measured at early times by resonant interferometry and Langmuir probe. This density decays to a value of about $10^{18} \mathrm{~m}^{-3}$ by $8 \mu \mathrm{s}$. Of particular interest for APII is the total number of ablated ions, which starts out at $4.6 \times 10^{14}$ at early times (resonant interferometry) and decays to $2.3 \times 10^{13}$ at the $8 \mu \mathrm{s}$ delay time at which the high voltage was typically applied for the parallel target-substrate orientation. Plasma temperature is in the $1 \mathrm{eV}$ range at microsecond delay times, both from Langmuir probe and optical emission spectroscopy. Plume expansion velocities indicate electron temperatures of $3 \mathrm{eV}$, from the expression for hydrodynamic expansion in vacuum

$$
V=2 c_{0} /(\gamma-1),
$$

where, $c_{0}$ is the ion sound speed $\left[\left(\gamma k T_{e} / M\right)^{1 / 2}\right]$ and $\gamma$ is the ratio of specific heats $\left(C_{p} / C_{v}\right)$, here $\gamma=1.2$.

In Table II are presented the ion doses determined by a number of different techniques, including: integrated ion current, sputtering yield, XEDS, and XPS. The delivered/ implanted ion doses are in the range from 2.5 to 6.36 $\times 10^{12}$ ions $/ \mathrm{cm}^{2}$ over a deposited film area of about $8 \mathrm{~cm}^{2}$. These implanted doses $\left(2-5 \times 10^{13}\right)$ can be compared to the 
TABLE I. Plasma diagnostic summary for Ablation Plasma Ion Implantation.

\begin{tabular}{|c|c|c|c|c|c|c|}
\hline Diagnostic & & $\begin{array}{l}\text { Ion density } \\
\left(\mathrm{m}^{-3}\right)\end{array}$ & $\begin{array}{l}\text { Electron density } \\
\qquad\left(\mathrm{m}^{-3}\right)\end{array}$ & $\begin{array}{c}\text { Electron temp. } \\
(\mathrm{eV})\end{array}$ & $\begin{array}{l}\text { Plume expansion } \\
\text { velocity } \\
\left(10^{4} \mathrm{~m} / \mathrm{s}\right)\end{array}$ & Total number of ions \\
\hline $\begin{array}{c}\text { Resonant } \\
\text { interferometry } \\
\left(5 \mathrm{~J} / \mathrm{cm}^{2}\right)\end{array}$ & & $\begin{array}{l}3.6 \times 10^{19}-1.0 \times 10^{20} \\
\quad(135-340 \mathrm{~ns})\end{array}$ & & & 1.13 & $\begin{array}{c}1.9 \times 10^{14}-4.6 \times 10^{14} \\
\quad(135-340 \mathrm{~ns})\end{array}$ \\
\hline $\begin{array}{l}\text { Nonresonant } \\
\text { interferometry } \\
\left(\mathrm{Fe}, 10 \mathrm{~J} / \mathrm{cm}^{2}\right)\end{array}$ & & & $\begin{array}{c}1 \times 10^{24}-2.2 \times 10^{23} \\
\quad(3-55 \mathrm{~ns})\end{array}$ & & & \\
\hline $\begin{array}{l}\text { Langmuir probe } \\
(3.3 \mathrm{~cm} \text { away from } \\
\left.\text { target, } 10 \mathrm{~J} / \mathrm{cm}^{2}\right)\end{array}$ & & $\begin{array}{c}1.0 \times 10^{20}-1.0 \times 10^{18} \\
(1-9 \mu \mathrm{s})\end{array}$ & $\begin{array}{c}4.6 \times 10^{17}-2.1 \times 10^{17} \\
(1-9 \mu \mathrm{s})\end{array}$ & $\begin{array}{c}1.2-0.7 \\
(1-9 \mu \mathrm{s})\end{array}$ & 5.9 & $2.3 \times 10^{13}(8 \mu \mathrm{s})$ \\
\hline $\begin{array}{c}\text { Ion } \\
\text { current } \\
(-10 \mathrm{kV})\end{array}$ & $\begin{array}{l}\| \\
\perp\end{array}$ & & & & & $\begin{aligned} & 1.8 \times 10^{12}-2.5 \times 10^{12} / \mathrm{cm}^{2}\left(5-15 \mathrm{~J} / \mathrm{cm}^{2}\right) \\
& 3.2 \times 10^{12}-4.4 \times 10^{12} / \mathrm{cm}^{2} \\
&\left(5-15 \mathrm{~J} / \mathrm{cm}^{2}\right)\end{aligned}$ \\
\hline $\begin{array}{l}\text { Optical emission } \\
\text { spectroscopy }\end{array}$ & & & & $\begin{array}{c}1.6-1 \\
(125-475 \mathrm{~ns})\end{array}$ & 2.25 & \\
\hline $\begin{array}{l}\text { Resonant } \\
\text { absorption } \\
\text { (DLRAP) }\end{array}$ & $\begin{array}{c}\text { Ion } \\
\text { Neutral }\end{array}$ & & & 2.9 & $\begin{array}{c}2.56-2.79 \\
\left(5-15 \mathrm{~J} / \mathrm{cm}^{2}\right) \\
0.82-1.68 \\
\left(5-15 \mathrm{~J} / \mathrm{cm}^{2}\right)\end{array}$ & \\
\hline
\end{tabular}

total number of ablated ions $\left(2-5 \times 10^{14}\right)$ from Table I to estimate the efficiency of APII. This analysis yields an APII efficiency in the range of $10 \%$ for the implantation of ions from laser ablation plumes.

Finally, we emphasize that the perpendicular targetsubstrate orientation has recently made it possible to perform APII with a dc power supply, without arcing. This could result in a much simpler and more economical APII system.

\section{ACKNOWLEDGMENTS}

The authors thank Steve Yalisove for many stimulating discussions. This research was supported by the National Science Foundation, Combustion and Plasma Systems Program in the Division of Chemical and Transport Systems; NSF Grant No. CTS-9907106.

\section{APPENDIX}

This Appendix presents a derivation of the scaling law for the implanted ion current for the geometry where the target is parallel to the substrate. In particular, this treats the case where the plasma plume is already in contact with the substrate when the bias voltage is turned on. In the experiment, the implanted ion current and the substrate current evolve on the time scale of the bias voltage (Fig. 2), which is on the order of $\mu$ s and is of a much longer time scale than $1 / \omega_{\text {pi }}$; the latter is of order 10 's of ns and is the time scale

TABLE II. The delivered ion dose and retained ion dose per pulse.

\begin{tabular}{lcccc}
\hline \hline & $\begin{array}{c}\text { Sputtering } \\
\text { yield } \\
\text { (delivered) }\end{array}$ & $\begin{array}{c}\text { XEDS } \\
\text { (delivered) }\end{array}$ & $\begin{array}{c}\text { XPS } \\
\text { (retained) }\end{array}$ \\
\hline $\begin{array}{l}\text { Ion dose } \\
\text { per pulse } \\
\left(10^{12} / \mathrm{cm}^{2}\right)\end{array}$ & 2.5 & 6.36 & 3.14 & 5.208 \\
\hline \hline
\end{tabular}

for the depletion of the ion matrix sheath. Thus, we need to develop a theory that applies to the long time ion implantation as observed in the experiments. Naturally, in the theory, we choose the time scale to be that of the bias voltage, which is roughly the $R C$ time constant $(\sim 1 \mu \mathrm{s})$ of the external circuit.

For the post ion-matrix-sheath implantation, it is commonly assumed that the ion current density at the sheath edge is due to the uncovering of the ions by the movement of the sheath, and to the ions carried across the sheath boundary at a velocity $\nu_{s}$, which is roughly the Bohm velocity. ${ }^{20,21}$ Equating this current density to the Child-Langmuir current, one obtains

$$
q n_{0}\left(\frac{d s}{d t}+\nu_{s}\right)=j_{i}=\frac{4}{9} \varepsilon_{0}\left(\frac{2 q}{M}\right)^{1 / 2} V_{s}^{3 / 2} / s^{2},
$$

where $V_{s}$ is the bias voltage and $s$ is the sheath width. Nondimensionalizing Eq. (A1)

$$
\bar{t}=t / \tau ; \bar{V}_{s}=V_{s}(t) / V_{0},
$$

and

$$
\bar{s}=s / L,
$$

where we may choose $\tau=R C$, the rise time of the bias voltage; $V_{0}$ is the peak voltage; and the length scale $L$ is chosen so that Eq. (A1) is nondimensional

$$
\begin{aligned}
L= & \left.\frac{4}{9} \varepsilon_{0} \sqrt{\frac{2 q}{M}} \frac{V_{0}^{3 / 2} \tau}{q n_{0}}\right)^{1 / 3} \\
= & (3.64 \mathrm{~mm})\left(\frac{1}{M / 50 m_{p}}\right)^{1 / 6}\left(\frac{V_{0}}{10 \mathrm{kV}}\right)^{1 / 2} \\
& \times\left(\frac{\tau}{1 \mu \mathrm{s}}\right)^{1 / 3}\left(\frac{1}{n_{0} / 10^{18} \mathrm{~m}^{-3}}\right)^{1 / 3},
\end{aligned}
$$


where $m_{p}$ is the proton mass, and the remaining symbols have their usual meanings. If we ignore the $\nu_{s}$ term in Eq. (A 1), Eq. (A1) is simplified to read

$$
\frac{d \bar{s}}{d \bar{t}}=\frac{\bar{V}_{s}^{3 / 2}}{\bar{s}^{2}} \equiv \overline{j_{i}(t)}
$$

and the normalized implanted ion current density can be expressed as

$$
\overline{j_{i}(t)}=j_{i}(t) \times \frac{\tau}{L q n_{0}} .
$$

Note that in Eq. (A4), the scale for the current density is $q n_{0} L / \tau$, which is naturally constructed from the velocity scale $L / \tau$. Physically, this current density scale gives the amount of ion charge that is transported to a unit area of the substrate, over the voltage risetime $\tau$ across the Child sheath of thickness $L$. If $A$ is the substrate area, the normalized implanted ion current scale is then $A q n_{0} L / \tau$, which becomes, upon substituting $\mathrm{L}$ and $\tau$

$$
\begin{aligned}
I_{i}= & (0.583 \mathrm{~A})\left(\frac{1}{M_{i} / 50 m_{p}}\right)^{1 / 6}\left(\frac{n_{0}}{10^{18} \mathrm{~m}^{-3}}\right)^{2 / 3} \\
& \times\left(\frac{V_{0}}{10 \mathrm{kV}}\right)^{1 / 2}\left(\frac{1}{\tau / 1 \mu \mathrm{s}}\right)^{2 / 3}\left(\frac{A}{10 \mathrm{~cm}^{2}}\right) .
\end{aligned}
$$

The sheath width $\bar{s}$ can easily be obtained by integrating Eq. (A3) once we specify the normalized bias voltage profile $V_{s}$. The normalized ion current density as a function of time is obtained by putting $\bar{s}$ back into Eq. (A3)

$$
\bar{j}_{i}(\bar{t})=\frac{\bar{V}_{s}(\bar{t})^{3 / 2}}{\left(\bar{s}_{\text {in }}^{3}+3 \int_{0}^{\bar{t}} \bar{V}_{s}(\bar{t})^{3 / 2} d \bar{t}\right)^{2 / 3}},
$$

where $\bar{s}_{\text {in }}$ represents the initial value of $\bar{s}$. In the numerical calculations given in Figs. 12(a) and 12(b), we arbitrarily take the normalized value $\bar{s}_{\text {in }}$ to be 0.1 , and the normalized bias voltage profile to be simply $\bar{V}_{s}(\bar{t})=1-e^{-\bar{t}}$. The implanted ion current, in dimensional form, is then given by multiplying Eq. (A6) by the current scale, Eq. (A5). This results in the theoretical implanted current shown in Fig. 12(b). The total substrate current [Fig. 12(a)] is obtained from Eq. (3) of the main text, using an empirical mode ${ }^{10}$ for the secondary electron emission coefficient $\delta$.

${ }^{1}$ J. R. Conrad, J. L Radtke, R. A. Dodd, J. Worzala, and N. C. Tran, J. Appl. Phys. 62, 4591 (1987).

${ }^{2}$ J. R. Conrad, U.S. Patent No. 4764394 (1988).

${ }^{3}$ J. T. Sheuer, M. Shamim, and J. R. Conrad, J. Appl. Phys. 67, 1241 (1990).

${ }^{4}$ R. P. Fetherston, M. M. Shamim, and J. R. Conrad, U.S. Patent No. 5693376 (1997).

${ }^{5}$ Handbook of Plasma Immersion Ion Implantation, edited by A. Anders (Wiley, New York, 2000).

${ }^{6}$ Y. X. Leng et al., Thin Solid Films 398 - 399, 471 (2001).

${ }^{7}$ S. Qin, N. McGruer, C. Chan, and K. Warner, IEEE Trans. Electron Devices 39, 2354 (1992).

${ }^{8}$ B. P. Wood, I. Henins, D. J. Rej, H. A. Davis, W. Waganaar, R. E. Muenchausen, G. P. Johnson, and H. K. Schmidt, Nucl. Instrum. Methods Phys. Res. B 96, 429 (1995).

${ }^{9}$ I. G. Brown, Rev. Sci. Instrum. 65, 3062 (1994).

${ }^{10}$ B. Qi, Ph.D. dissertation, University of Michigan, 2002

${ }^{11}$ B. Qi, R. M. Gilgenbach, Y. Y. Lau, M. D. Johnston, J. Lian, L. M. Wang, G. L. Doll, and A. Lazarides, Appl. Phys. Lett. 78, 3785 (2001).

${ }^{12}$ B. Qi, Y. Y. Lau, and R. M. Gilgenbach, Appl. Phys. Lett. 78, 706 (2001).

${ }^{13}$ R. M. Gilgenbach, C. H. Ching, J. S. Lash, and R. A. Lindley, Phys. Plasmas 1, 1619 (1994).

${ }^{14}$ R. A. Lindley, R. M. Gilgenbach, C. H. Ching, J. S. Lash, and G. L. Doll, J. Appl. Phys. 76, 5457 (1994).

${ }^{15}$ H. Spindler, R. M. Gilgenbach, and J. S. Lash, Appl. Phys. Lett. 68, 3245 (1996).

${ }^{16}$ M. A. Lieberman, J. Appl. Phys. 66, 2926 (1989).

${ }^{17}$ K.-U. Riemann, J. Phys. D 24, 493 (1991).

${ }^{18}$ N. Hershkowitz, L. Oksuz, A. M. Hala, and M. A. Khedr, IEEE International Conference on Plasma Science, June 4-7, 2000, New Orleans, LA, p. 227.

${ }^{19}$ S. Masamune, and K. Yukimura, Rev. Sci. Instrum. 71, 1187 (2000).

${ }^{20}$ W. G. En, M. A. Lieberman, and N. W. Cheung, IEEE Trans. Plasma Sci. 23, 415 (1995).

${ }^{21}$ M. A. Lieberman and A. J. Lichtenberg, Principles of Plasma Discharges and Materials Processing (Wiley, New York, 1994). 